\title{
Germs, governance, and global public health in the wake of SARS
}

\author{
David P. Fidler \\ Indiana University School of Law, Bloomington, Indiana, USA, and Centre for International Studies, University of Oxford, Oxford, United Kingdom.
}

\begin{abstract}
A revolution in the governance of global infectious disease threats is under way, accelerated by events triggered by the outbreak of SARS in 2003. This review article analyzes pre-SARS trends in the governance of infectious diseases, examines the impact of the SARS outbreak on these trends, and posits that germ governance is now a criterion of "good governance" in world affairs.
\end{abstract}

The study of infectious diseases has traditionally focused on scientific and medical issues, and advances in biotechnology suggest that new, perhaps revolutionary, scientific and medical developments are on the horizon. Important as these developments might become, another revolution is under way in a historically neglected areagovernance of global infectious disease threats. Public health has experienced a governance revolution of such significance that infectious disease control now represents an important criterion of "good governance" in world affairs. This development is historically unprecedented and deserves more consideration and critical analysis than it has received to date.

This article is presented in three parts: (i) a description of discernable trends in the governance of infectious disease control prior to the outbreak of severe acute respiratory syndrome (SARS) in 2003; (ii) an analysis of how the global containment of SARS has affected these trends; and (iii) a discussion of how, in the wake of SARS, infectious disease control has emerged onto the "good governance" agenda that developed in other areas of post-Cold War international relations.

\section{Germs and governance}

"Governance" refers to how societies structure responses to the challenges they face. Analyses of emerging and re-emerging infectious diseases (EIDs) have made clear that national and international societies are confronting increased microbial threats (1-3). The US Institute of Medicine has argued that the world faces successive "perfect microbial storms" (4). Whether the focus is bioterrorism, HIV/AIDS, SARS, or avian influenza, germs increasingly pose dangers to human societies.

"Germ governance" concerns how societies, both within and beyond national borders, structure their responses to pathogenic challenges. Governance involves government, but the concepts are not synonymous. Making them synonymous would mean governance cannot exist in international relations because no world government exists. The global nature of the microbial threat requires that governance address the borderless challenges presented by infectious diseases.

\section{Horizontal and vertical germ governance}

Historically, public health governance has been divided into governance within states and governance between states. In terms of germ

Nonstandard abbreviations used: emerging and re-emerging infectious disease (EID); global public goods for health (GPGH); International Health Regulations (IHR); International Monetary Fund (IMF); nongovernmental organization (NGO); severe acute respiratory syndrome (SARS); Trade-Related Aspects of Intellectual Property Rights (TRIPS); World Trade Organization (WTO).

Conflict of interest: The author has declared that no conflict of interest exists. Citation for this article: J. Clin. Invest. 113:799-804 (2004). doi:10.1172/JCI200421328. governance, two strategies have developed during the course of international efforts on infectious diseases - horizontal and vertical.

Horizontal germ governance. Horizontal strategies concentrated on states as the dominant actors, focused on threats that complicated trade and travel between states, and utilized international law to structure cooperation on public health problems (Figure 1) (5). This approach conceptualized infectious diseases as exogenous threats to a state's national interests that could only be mitigated through international cooperation (6). How a country organized public health internally was not a subject of horizontal germ governance. Horizontal strategies largely served the trade interests of the strongest countries in the international system - the great powers - and dominated international cooperation on public health from the mid-19th century until the end of World War II (7).

The WHO's International Health Regulations (IHR), first adopted as the International Sanitary Regulations in 1951, provide the best contemporary example of the horizontal germ governance approach. The IHR continue the governance approach developed in the international sanitary conventions of the late 19th and first half of the 20th century. The IHR's objective is to ensure the maximum security against the international spread of diseases with minimum interference with world trade and travel (8). The IHR identified specific infectious diseases (e.g., cholera, plague, and yellow fever) and required WHO Member States to report outbreaks of these diseases and to limit trade- and travel-restricting health measures taken in response to outbreaks in other countries to those prescribed in the Regulations (8) (see box, The WHO's International Health Regulations).

Vertical germ governance. Vertical strategies conceptualize infectious diseases as threats within states rather than as exogenous threats to a state's interests and power (5). The objective is not to manage germ traffic between states but to reduce disease threats within states (Figure 2). The human right to health strongly influenced the development of the vertical germ governance approach; and this right requires scrutiny of domestic health systems, a feature not present in the horizontal approach (6). Vertical germ governance developed in the post-World War II period, as illustrated by: (i) the turn by the WHO away from horizontal strategies and toward disease eradication and access to primary health care (9); and (ii) the prominence of human rights concepts, such as the right to health, seen in the WHO's "Health for All" campaign (10) and the global strategy for the control of HIV/AIDS (11). The vertical approach highlighted the inadequacy of domestic public health systems in developing countries. Vertical approaches sought to include non-state actors, such as nongovernmental organizations (NGOs), thus challenging the state's monopoly on germ gover- 


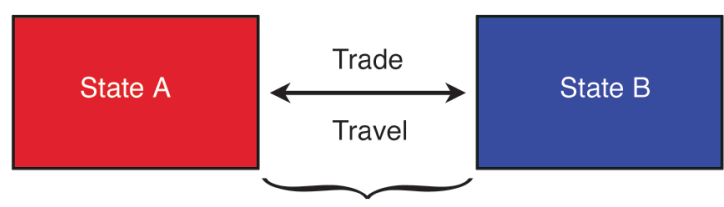

Regulating microbial traffic between states

\section{Figure 1}

Horizontal germ governance focuses on infectious disease threats moving between states through international trade and travel and developed through international sanitary conventions adopted in the late 19th and first half of the 20th centuries; this approach is currently applied in the WHO's IHR.

nance prevalent in the horizontal strategy. During the post-World War II period when both horizontal and vertical approaches operated, no synthesis of these frameworks occurred.

\section{The impact of EIDs}

Prior to the 1990s, infectious disease control, of whatever variety, was a neglected aspect of international relations. Although international cooperation on infectious diseases had been occurring since the mid-19th century, germ governance never represented "high politics" between states and was of little interest to scholars of world politics (12). Concern about infectious diseases developed in the 1990s and early 21 st century as EIDs, such as HIV/AIDS, tuberculosis, and malaria, increased the global microbial threat. During this period, germ governance received more attention, resulting in a higher political profile for infectious disease control. In this ferment concerning infectious diseases, important trends emerged.

In terms of horizontal governance, the traditional regime for infectious disease control, the WHO's IHR (8), diminished in importance for many reasons, including the IHR's application to only a small number of diseases. International trade law, as found in the agreements of the World Trade Organization (WTO), grew in significance because of the adoption of new agreements that directly affected the relationship between trade and public health (5). Largely because of the HIV/AIDS pandemic, vertical strategies, especially the human rights approach, gained strength, particularly concerning access to antiretroviral drug therapy in developing countries (5). The battle over the impact of the WTO's Agreement on Trade-Related Aspects of Intellectual Property Rights (TRIPS) on access to essential medicines represented a clash between traditional horizontal and vertical approaches (see box, The WTO's TRIPS Agreement).

Despite this clash, bifurcation of horizontal and vertical strategies began to break down into a hybrid approach that exhibits characteristics from both strategies. The first aspect of this hybrid strategy involved a move from "international governance" toward "global governance." International governance is defined as governance among sovereign states (including intergovernmental organizations, such as the UN, WHO, and WTO) (13) and is essentially the same concept as horizontal governance. Global governance refers to the involvement of not only states and intergovernmental organizations but also non-state actors, such as NGOs (e.g., Médecins Sans Frontières) and multinational corporations (e.g., pharmaceutical companies) (13). Global governance incorporates non-state actors and radically differs from state-centric horizontal strategies because it posits that governments alone cannot handle global microbial threats.
The vertical process of global governance was, however, harnessed to the traditional horizontal objective of mitigating transboundary microbial traffic. The WHO's decision in 1995 to revise the IHR revealed the growing importance of global governance in interstate disease control. A key change proposed by the WHO was to allow the WHO to use information from nongovernmental sources for epidemiological surveillance of infectious disease outbreaks (14). This proposal would terminate the existing IHR's sole reliance on government-provided surveillance information. In short, states would be better protected from microbial traffic by ending the state's monopoly on disease surveillance.

The second aspect of the hybrid strategy involved the substantive outcomes of germ governance. Horizontal strategies traditionally sought to reduce: (i) the economic burden that public health measures imposed on trade and travel; and (ii) a state's vulnerability to microbial importation. The objective of this approach was to protect mainly developed countries (6). Influenced by the notion of human rights, vertical governance traditionally sought to improve individual health status, particularly in developing countries (6). In the last decade, a hybrid objective - global public goods for health (GPGH) - arose. GPGH have been variously defined, but the basic concept focuses on producing goods (e.g., antimicrobial drugs) and services (e.g., surveillance), the consumption of which is non-rival and non-excludable, across different geographical regions (15). The concept of GPGH is more expansive than the national interest paradigm of horizontal governance but less universal than the human rights approach of vertical governance. Analyses of global infectious disease problems, such as the report by the WHO's Commission on Macroeconomics and Health (16), advocated increasing GPGH production. Mechanisms developed for this purpose included the establishment of public-private partnerships (17) (e.g., the Global Fund to Fight AIDS, Tuberculosis, and Malaria), which proliferated to such an extent that the WHO observed that these partnerships were improving the landscape of infectious disease control (3).

Finally, another significant development in infectious disease policy in the 1990 s and early 21 st century was bioterrorism. Even before the anthrax attacks in the United States in 2001, bioterrorism fears had risen in the United States and other countries (18). Experts realized that bioterrorism preparedness called for robust public health systems, especially surveillance (19). Countries fearful of bioterrorism, particularly the United States, launched initiatives to improve domestic public health capabilities and international cooperation on bioterrorism preparedness

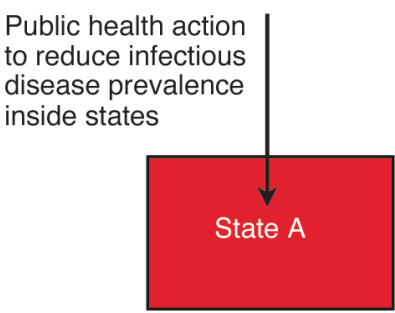

\section{Figure 2}

Vertical germ governance focuses on reducing the infectious disease prevalence inside states rather than regulating the transboundary movement of pathogenic microbes and is the approach taken in the promotion of the right to health, disease eradication programs, and programs to increase access to primary health care and essential medicines. 


\section{The WHO's International Health Regulations}

The WHO's IHR are currently the only set of international legal rules on infectious disease control binding on WHO Member States. In 1951, the WHO decided to consolidate into a universal set of rules a number of sanitary conventions that had been adopted from the late 19th century through World War II; these new rules, called the International Sanitary Regulations, were later renamed (in 1969) the International Health Regulations. The WHO last revised the IHR in 1981, when smallpox was removed from the list of infectious diseases subject to the regulations. Currently, the IHR apply to only three diseases cholera, plague, and yellow fever. WHO Member States are required to notify the WHO of outbreaks of these diseases and not to punish afflicted countries with trade- or travel-restricting measures that are more restrictive than those prescribed in the IHR. In 1995, the WHO began a process of revising the IHR in order to deal with the challenges of infectious disease control in the era of globalization. The WHO expects to complete this revision process in 2005.

(see box, Bioterrorism's impact on germ governance). These developments connected germ governance to national security, an unprecedented circumstance for public health (20).

The ferment concerning infectious disease control suggested that a new governance era was developing. Approaches such as global health governance and GPGH gave momentum to hybrid strategies; but the effectiveness and sustainability of these new ideas remained unclear. Initiatives created to address HIV/AIDS provided a troubling example of the uncertain impact of public-private partnerships on germ governance. For example, as 2003 began, the Global Fund to Fight AIDS, Tuberculosis, and Malaria reported that it was nearly bankrupt because financial contributions from states were inadequate (21). If the emerging strategies of germ governance could not handle the strain of existing microbial problems, what would happen when the next infectious disease crisis broke upon the world?

\section{The impact of the SARS outbreak on germ governance}

The SARS outbreak of 2003 had profound impact on approaches to infectious disease control. This author has written at length elsewhere about SARS' impact on governance and the globalization of infectious diseases $(22,23)$, and has argued that the SARS outbreak represents "the coming-of-age of a governance strategy for infectious diseases more radical than any previous governance innovation in this area of international relations" (23). The following section highlights the governance revolution triggered by the global containment of SARS.

According to the WHO, SARS was the first severe infectious disease to emerge in the globalized society of the 21 st century (24). Although SARS had features, such as its cross-border mobility, similar to those of diseases subject to horizontal governance in the past, the mechanisms of such governance were irrelevant to SARS. Because SARS was a new syndrome, it was not a disease subject to the IHR; thus, these rules were not applicable to the global control of SARS. The SARS outbreak put the final nail in the coffin of relying on traditional horizontal strategies for germ governance, for three reasons.

First, the global campaign to control SARS demonstrated the power of global health governance mechanisms. The WHO's ability to access nongovernmental sources of epidemiological informa- tion (e.g., media reports, e-mails, and the Internet) played a critical role in SARS' containment. In dealing with the Chinese government's unwillingness to report openly the scale of China's SARS problem, the WHO benefited from access to nongovernmental information (e.g., from individual Chinese doctors and media reports) about the extent of the SARS problem in China (23). In an example of historic miscalculation, China attempted to maintain control of epidemiological information in a context saturated by the Internet, e-mail, and mobile phones. China's initial refusal to notify the WHO of suspected and confirmed SARS cases in a timely, transparent, and verifiable manner ran headlong into the global governance mechanism of the WHO's integration of nongovernmental information into global infectious disease surveillance.

Equally important was the effect such integration had on other states. Despite not being under any legal obligation to report SARS cases, every state affected by SARS (except China) reported this information to the WHO early and rapidly. Such behavior by states during a serious outbreak was unprecedented. This astonishing situation reflects the realization that epidemiological information in the global age does not, and will not, respect sovereignty. The incorporation of nongovernmental information into surveillance elevates the importance of non-state actors in germ governance and constricts state sovereignty concerning outbreak management.

Second, the global campaign to control SARS demonstrated the power of GPGH in the context of a dangerous epidemic. The WHO coordinated efforts to produce GPGH as part of the attempt to contain SARS in three areas: the production of (i) surveillance information; (ii) scientific research on the causative agent of SARS; and (iii) guidelines regarding the clinical management of SARS cases (23). Just as with the surveillance achievements, the degree of global cooperation on identifying the causative agent of SARS and developing guidelines for the clinical treatment of infected patients was unprecedented. Production of these GPGH occurred through the participation of states, intergovernmental organizations, and nonstate actors, and thus represents further evidence for the need for hybrid germ governance strategies.

Third, the SARS epidemic induced the WHO to exercise unprecedented power against states affected by an infectious disease. Under the terms of traditional horizontal governance, states restrict the authority of intergovernmental organizations in order to maintain maximum flexibility for sovereignty (23). During the SARS outbreak, however, the WHO independently issued global

\section{The WTO's TRIPS Agreement}

The WTO's TRIPS Agreement harmonizes intellectual property rights among WTO Member States, including patent rights, by establishing minimum levels of protection that each WTO Member State must give to the intellectual property of other WTO Member States. The TRIPS Agreement contains safeguards, such as the rights to engage in parallel licensing and compulsory licensing that allow WTO Member States to address public health problems. Despite the existence of these safeguards, the TRIPS Agreement became the source of public health controversy in connection with efforts to increase access to essential medicines, such as patented antiretrovirals, in developing countries. This controversy eventually produced the WTO's Doha Declaration on the TRIPS Agreement and Public Health in 2001, which stated that the TRIPS Agreement does not and should not prevent WTO Member States from taking measures to protect public health. 


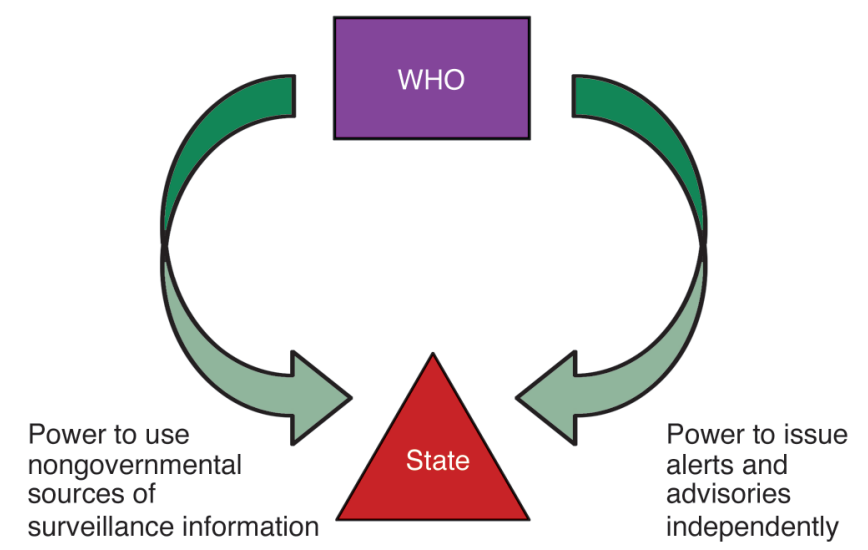

Figure 3

The global health governance "pincer" captures how the WHO's power to use nongovernmental sources of surveillance information on infectious diseases and to issue alerts and advisories independently of its Member States reduces the sovereign state's discretion in how it responds to infectious disease outbreaks.

alerts and geographically specific travel advisories (25) that caused affected states economic damage. The travel advisories were particularly radical, for three reasons.

First, neither the WHO Constitution nor the IHR grant the WHO independent authority to recommend that travelers postpone nonessential travel to WHO Member States affected by an epidemic (26). The WHO itself had not even included such authority in its preSARS proposals to revise the IHR (14). Under those proposals, any WHO recommendations concerning an outbreak of international concern would be issued with the advance agreement of the country or countries affected (14). In issuing alerts and advisories regarding SARS, the WHO acted independently, without the consent (or even the consultation) of targeted countries.

Second, through the alerts and advisories, the WHO exercised power against its Member States. These actions resulted in political and economic damage in the states concerned. One would search the annals of international organizations in vain to find examples of such an organization wielding real power against multiple Member States without express authorization. Although the states affected by these advisories complained (e.g., Canada) about the WHO's actions (26), none publicly challenged such radical governance behavior by the WHO during the outbreak. At the World Health Assembly meeting in May 2003, the Member States of the WHO formally empowered it to take such actions in the future when necessary (27).

Third, the WHO issued travel advisories directly to non-state actors - travelers - rather than directing its recommendations to Member States (23). This action revealed that during the SARS outbreak, the WHO governed using principles that resonated with vertical rather than horizontal strategies. Not only did non-state actors play a pivotal role in SARS surveillance but they also were direct subjects of WHO governance actions.

From a governance perspective, the WHO's power to use nongovernmental sources of information and to issue alerts and advisories created a global health governance "pincer" (Figure 3) (23). The pincer squeezes state sovereignty by using nongovernmental sources of surveillance information to minimize a state's discretionary power to report or withhold information about outbreaks, and by increas- ing political and economic incentives for participation in global cooperation in order to maximize the prospects of domestic containment of a pathogenic threat and thus avoid advisories.

The governance response to SARS also brought into play the notion of human rights (23), which was a prominent factor in the development of vertical strategies. Global HIV/AIDS policy has, since the late 1980s, stressed respect for civil and political rights (e.g., non-discrimination) and the right to health (e.g., access to primary health care and treatment) (28). SARS was a novel pathogen for which no adequate diagnostic, vaccine, or therapeutic technologies existed (25). SARS containment depended on isolation and quarantine in many countries, which raised questions about the precautions required to ensure public health while protecting human rights (23). The concerns expressed about human rights in connection with SARS isolation and quarantine would not arise under traditional horizontal governance. In the SARS outbreak, unlike in the case of HIV/AIDS, infringements of human rights were largely thought justified in order to facilitate domestic containment and mitigation of transboundary spread.

Although this overview only highlights some features of SARS' impact on germ governance, it provides a glimpse into a radical and unprecedented event in the history of governance of infectious diseases. SARS is seminal in another respect: the outbreak put infectious disease control on the agenda of "good governance" in world politics.

\section{Germs and "good governance"}

The post-Cold War period saw "good governance" promoted within transition and developing countries by developed states and international development organizations, such as the World Bank (29) and the International Monetary Fund (IMF) (30). Good governance is a complex concept, but it essentially represents a set of procedural and substantive indicators by which to measure the quality of a country's governance. Procedurally, good governance requires, for example, participatory, accountable, and transparent governance. Substantively, good governance involves democracy, the rule of law, market-based economics, and the protection of human rights.

Health's place in the the good governance project evolved over time. Critics assailed early good governance policies, such as IMF demands that developing countries restructure their economic policies in return for financial assistance (i.e., structural adjustment policies), for having adverse health consequences in developing countries because of a myopic focus on economic criteria (31). The prominence of health issues increased as experts connected the achievement of good governance with positive health outcomes. A

\section{Bioterrorism's impact on germ governance}

The growing threat of bioterrorism has significantly affected germ governance, especially in the United States. To combat the bioterrorist threat, the US federal government has allocated more money to improve bioterrorism preparedness and response capabilities at federal and state levels, passed new statutes to empower federal agencies to respond more effectively to bioterrorism, and launched new programs, such as the smallpox vaccination campaign, to reduce US vulnerability to bioterrorist attack. The United States has also led efforts to intensify international cooperation against bioterrorism, as illustrated by the establishment of a Global Health Security Initiative among the G-8 countries and Mexico and cooperation with the WHO on bioterrorism preparedness and response. 
US interagency task force wrote in 1995 that, because civil instability and strife provide breeding grounds for microbes, "efforts to promote good governance... are not out of place in a discussion of how to deal with new and re-emerging diseases" (32). Such good governance-health linkages asserted that better public health would flow from progress towards good governance but did not maintain that public health was itself a good governance indicator.

Health's rise as a good governance issue also appeared in the context of foreign aid when donor countries and international organizations began to require that aid-recipient countries increase investments in the health sector. The Bush administration's Millennium Challenge Account, from which developmental assistance is provided to those countries that rule justly, invest in their people, and encourage economic freedom, requires, for example, that recipient countries invest in health to be eligible for US aid (33). Such requirements factored increased commitment to health into calculations concerning good governance reforms in developing countries.

The developments traced above concerning infectious disease control deepen the good governance-health relationship by making public health an independent criterion of good governance. In other words, without good germ governance a country does not have good governance. This perspective radically differs from hopes that good governance reforms will produce better public health or from equating increased investments in health as evidence of good governance. The perspective is radical because it posits that public health is itself, like democracy and the rule of law, an indicator of good governance.

The severity of the infectious disease threat supports elevating public health in this way. Experts have argued that infectious diseases pose direct and indirect threats to basic functions of governance, including political institutions (34), economic development (16), the protection of human rights (35), and national security $(20,36)$. Reflecting on the HIV/AIDS pandemic in developing countries, US Secretary of State Colin Powell has argued, for example, that "HIV/AIDS carries profound implications for prosperity, democracy and security" (37).

When confronting the microbial menace, it is not sufficient to argue that democratic reforms and larger health budgets will produce infectious disease control. South Africa's HIV/AIDS disaster has occurred under a democratically elected government. SARS pushed Canada's expensive system of universal health care to the brink, prompting the government to review the nation's public health policy and infrastructure (26). Upon reflecting on SARS, WHO officials stressed the critical general governance role of infec- tious disease control in arguing that " $\mathrm{t}]$ he SARS experience... made one lesson clear early in its course: inadequate surveillance and response capacity in a single country can endanger national populations and the public health security of the entire world" (38). A concept of good governance not informed by germ governance is flawed from the perspectives of democracy, human rights, economic development, and national security, all of which experts believe are threatened by resurgent infectious diseases.

\section{Conclusion}

Germ governance in the wake of SARS is at a revolutionary moment. The evolution of germ governance before and during SARS, and the elevation of such governance as an element of good governance, place public health in exciting but uncharted waters. In the aftermath of SARS, public health can no longer be considered a secondary priority at any level. In the post-SARS environment, the Canadian National Advisory Committee on SARS and Public Health stressed the importance of public health in governance by quoting Benjamin Disraeli's argument that "public health was the foundation for 'the happiness of the people and the power of the country. The care of the public health is the first duty of the statesman' " (26). Although germ governance has not achieved this level of importance, it has become an increasingly significant benchmark against which the health of national, international, and global governance is measured.

Revolutions do not always end happily, and the revolutionary moment for germ governance may be short-lived because the momentum of the new, radical developments and hybrid strategies may prove to be unsustainable. Countries have begun, for example, to formally question aspects of the WHO's travel advisory power (39). In addition, no one should have any illusions of the Herculean implications, particularly for building public health capacity in developing countries, of maintaining that public health constitutes an independent factor for assessing the quality of governance in an era of a resurgent microbial threat. The recent avian influenza scare in Asia provides further evidence of the dangerous times germ governance faces. Solidifying, sustaining, and advancing the germ governance revolution constitutes a seminal challenge for 21 st-century humanity.

Address correspondence to: David P. Fidler, Indiana University School of Law, 211 South Indiana Avenue, Bloomington, Indiana 47405, USA. Phone: (812) 855-6403; Fax: (812) 855-0555; E-mail: dfidler@indiana.edu.
1. 1992. Emerging infections: microbial threats to health in the United States. J. Lederberg, R.E. Shope, and S.C. Oaks, editors. National Academy Press. Washington, D.C., USA. 312 pP.

2. 1999. Removing obstacles to healthy development. World Health Organization. Geneva, Switzerland. 68 pp.

3. 2003. Global defence against the infectious disease threat. M.K. Kindhauser, editor. World Health Organization. Geneva, Switzerland. 242 pp.

4. 2003. Microbial threats to health: emergence, detection, and response. M.S. Smolinski, M.A. Hamburg, and J. Lederberg, editors. National Academy Press. Washington, D.C., USA. 367 pp.

5. Fidler, D.P. 2003. Emerging trends in international law concerning global infectious disease control. Emerging Infect. Dis. 9:285-290.

6. Fidler, D.P. 2004. Caught between paradise and power: public health, pathogenic threats, and the axis of illness. McGeorge Law Review. In press.

7. Howard-Jones, N. 1975. The scientific background of the
International Sanitary Conferences 1851-1938. World Health Organization. Geneva, Switzerland. 110 pp.

8. 1983. International Health Regulations (1969). 3rd annotated edition. World Health Organization. Geneva, Switzerland. 79 pp.

9. Arhin-Tenkorang, D., and Conceição, P. 2003 Beyond communicable disease control: health in the age of globalization. In Providing global public goods: managing globalization. I. Kaul, P. Conceição, K. Le Goulven, and R.U. Mendoza, editors. Oxford University Press. Oxford, United Kingdom. 484-515.

10. 1978. Declaration of Alma Ata. In Report of the International Conference on Primary Health Care. World Health Organization. Geneva, Switzerland. 79 pp.

11. Mann, J.M. 1999. Human rights and AIDS: the future of the pandemic. In Health and human rights: a reader. J.M. Mann, S. Gruskin, M.A. Grodin, and G.J. Annas, editors. Routledge. London, United Kingdom. 216-226.

12. Lee, K., and Zwi, A. 2003. A global political economy approach to AIDS: ideology, interests, and implications. In Health impacts of globalization: toward global governance. Palgrave Macmillan. London, United Kingdom. 13-32.

13. Dodgson, R., Lee, K., and Drager, N. 2002. Global health governance: a conceptual overview. Centre on Global Change \& Health. London, United Kingdom. World Health Organization. Geneva, Switzerland. 35 pp.

14. 2002. Global crises, global solutions: managing public bealth emergencies of international concern through the revised International Health Regulations. World Health Organization. Geneva, Switzerland. 28 pp.

15. Smith, R., and Woodward, D. 2003. Global public goods for health: use and limitations. In Global public goods for health: health economic and public health perspectives. R. Smith, R. Beaglehole, D. Woodward, and N. Drager, editors. Oxford University Press. Oxford, United Kingdom. 246-265.

16. Commission on Macroeconomics and Health. 2001 Macroeconomics and health: investing in bealth for eco- 
nomic development. World Health Organization. Geneva, Switzerland. 210 pp.

17. 2002. Public-private partnerships for health. M. Reich, editor. Harvard University Press. Cambridge, Massachusetts, USA. 208 pp.

18. Carter, A., Deutch, J., and Zelikow, P. 1998. Catastrophic terrorism: tackling the new danger. Foreign Affairs. 77:80-94.

19. Heymann, D.L. 2003. Emerging and epidemic-prone diseases: threats to public health security. In Biological security o public health: in search of a global treatment. K.M. Campbell and P. Zelikow, editors. Aspen Institute. Washington, D.C., USA. 49-55.

20. Fidler, D.P. 2003. Public health and national security in the global age: bioterrorism, pathogenic microbes, and Realpolitik. George Washington International Law Review. 35:787-856.

21. Global Fund to Fight AIDS, Tuberculosis, and Malaria. 2003. Press Release: Global Fund awards $\$ 866$ million in grants to fight AIDS, TB and malaria; United States takes chair of Global Fund Board; Tommy Thompson is elected. Jan. 31. http://www. globalfundatm.org/journalists/press\%20releases/pr_ 030131b.html.

22. Fidler, D.P. 2003. SARS: political pathology of the first post-Westphalian pathogen. J. Law Med. Ethics. 31:485-505.

23. Fidler, D.P. 2004. SARS, governance and the globalization of disease. Palgrave Macmillan. London, United
Kingdom. In press.

24. 2003. Severe Acute Respiratory Syndrome (SARS). Resolution of the Fifty-Sixth World Health Assembly. World Health Assembly, WHA56.29. May 28. Geneva, Switzerland. 4 pp.

25. 2003. Severe Acute Respiratory Syndrome (SARS): status of the outbreak and lessons for the immediate future. World Health Organization. Geneva, Switzerland. 13 pp.

26. National Advisory Committee on SARS and Public Health. 2003. Learning from SARS: renewal of public bealth in Canada. Health Canada. Ottawa, Canada. 234 pp.

27. 2003. Revision of the International Health Regulations. Resolution of the Fifty-Sixth World Health Assembly, WHA56.28. May 28. Geneva, Switzerland. 3 pp.

28. UNAIDS. HIV/AIDS, Human Rights \& Law. http:// www.unaids.org/en/in+focus/hiv_aids_human_ rights.asp.

29. World Bank. 1994. Development in practice: governance - the World Bank's experience. World Bank. Washington, D.C., USA. 86 pp.

30. International Monetary Fund. 1997. Good governance: the IMF's role. International Monetary Fund. Washington, D.C., USA. 14 pp.

31. Fidler, D.P. 1999. Neither science nor shamans: globalization of markets and health in the developing world. Indiana Journal of Global Legal Studies. 7:191-224.

32. National Science and Technology Council Commit- tee on International Science, Engineering, and Technology (CISET) Working Group on Emerging and Re-Emerging Infectious Diseases. 1995. Infectious diseases - a global health threat. CISET. Washington, D.C., USA. 55 pp.

33. Millennium Challenge Account. http://www.mca.gov. 34. Price-Smith, A.T. 2002. The health of nations: infectious disease, environmental change, and their effects on national security and development. The MIT Press. Cambridge, Massachusetts, USA. 232 pp.

35. Gruskin, S., and Tarantola, D. 2002. Health and human rights. In Oxford Textbook of Public Health. 4th edition. R. Detels et al., editors. Oxford University Press. Oxford, United Kingdom. 311-335.

36. Brower, J., and Chalk, P. 2003. The global threat of new and reemerging infectious diseases: reconciling U.S. national security and public bealth policy. RAND. Santa Monica, California, USA. 166 pp.

37. Powell, C. 2003. Remarks at Bill Signing Ceremony for the U.S. Leadership Against HIV/AIDS, Tuberculosis, and Malaria Act of 2003. May 27. http://www. state.gov/secretary/rm/2003/20969.htm.

38. Heymann, D.L., and Rodier, G. 2003. Global surveillance, national surveillance, and SARS. Emerging Infect. Dis. Feb. http://www.cdc.gov/ncidod/EID/ vol10no2/03-1038.htm

39. Reuters. 2004. WHO urged to ease up on travel alerts. Jan. 22. http://www.cnn.com/2004/HEALTH/ 01/22/WHO.warnings.reut/index.html. 